\title{
The Normative Value of Acceptable Noise Level Test for Korean Young Listeners with Normal Hearing and Its Relationship with Auditory Brainstem Response Latency
}

\author{
Yong-Hwi An, Eun Sub Lee, and Hyun Joon Shim \\ Department of Otorhinolaryngology, Eulji Medical Center, Eulji University School of Medicine, Seoul, Korea
}

\author{
정상 청력인 한국인 젊은 성인에서의 수용소음레벨 검사의 정상 범위 및 청성뇌간반응 잠복기와의 관계 \\ 안용휘 · 이은섭 · 심현준 \\ 을지대학교 의과대학 을지병원 이비인후과학교실
}

Received July 25, 2016

Revised November 7, 2016

Accepted November 9, 2016

Address for correspondence

Yong-Hwi An, MD

Department of Otorhinolaryngology,

Eulji Medical Center,

Eulji University School of Medicine,

68 Hangeulbiseok-ro, Nowon-gu,

Seoul 01830, Korea

Tel +82-2-970-8276

Fax $+82-2-970-8275$

E-mail an0072@hanmail.net
Background and Objectives Acceptable noise level (ANL) test has been developed as a method to measure the background noise acceptance when listening to speech presented at the most comfortable level. The study was aimed to investigate normal-hearing in young subjects' performance on ANL test and to evaluate the relationship between ANL and auditory evoked potentials.

Subjects and Method Fifty-three young adults (23 male and 30 female; aged 21 to 39 years) with normal hearing participated in this study. ANL and auditory brainstem response (ABR) tests were administered to subjects who were certified by pure tone audiometry that they had normal hearing threshold.

Results The ANL test showed a large inter-subject variability in the acceptance of background noise, ranging from -5 to $15 \mathrm{~dB}$ with the mean of ANL of $5.0 \pm 4.1 \mathrm{~dB}(4.5 \pm 4.5 \mathrm{~dB}$ in male and $5.4 \pm 3.8 \mathrm{~dB}$ in female). The mean most comfortable listening level was $35.2 \pm 5.3 \mathrm{~dB}$, and the mean background noise level was $30.2 \pm 6.1 \mathrm{~dB}$. There were no significant differences between male and female in the parameters of ANL test. There were no differences between the subjects with low versus high ANLs and ABR latencies.

Conclusion We obtained the normative data of the ANL test administered to Korean young adults with normal hearing. There is no relationship between ANL and the latency of ABR in this study population.

Korean J Otorhinolaryngol-Head Neck Surg 2016;59(12):825-30

\section{서 론}

일상 생활에서의 청각은 대부분 소음 속에서 이루어지며, 종종 그 소음의 강도는 청각 역치보다 강한 소리일 수 있다. 일반적으로 음량이 매우 큰 소리, 불협화음, 높은 주파수의 음 등이 소음으로 분류될 수 있지만, 구체적으로 무엇을 소 음으로 인식하거나 불편하다고 느끼느냐 하는 것은 개인의 성향이나 심리 상태에 따라서 다르다. 왜냐하면, 청력은 귀의 청각기관만을 이용하여 단순히 소리를 감지하는 것이 아니
라 청각 및 기억, 감정 중추 등과 관련된 대뇌의 기능이 통합 된 능력이기 때문이다. 따라서 순음청력검사와 같은 전통적 인 검사 방법으로는 청각능력을 충분히 측정하기 어려울 뿐 만 아니라 난청 환자들이 일상적으로 경험하게 되는 장애의 정도를 정량화하기 어렵다. ${ }^{1)}$ 이러한 청각능력을 올바르게 측 정하기 위해서는 소음 상황에서 언어 소통능력을 평가하는 검사법으로 언어인지검사(speech reception test)를 변형한 hearing in noise test가 개발되었고 한국어로도 제작되었다. ${ }^{2}$ Hearing in noise test가 소음 상황에서의 문장이해도를 검사 
하는 반면, loudness discomfort level 등 소음 자체를 얼마 나 수용할 수 있는지 측정하는 것도 임상적으로 도움을 줄 수 있다. ${ }^{3)}$

수용소음레벨(acceptable noise level, ANL)은 목표 이야 기(target story)와 배경 화자 잡음(babble noise)을 들려주어 청취자가 이야기를 따라갈 수 있는 동시에 수용할 수 있는

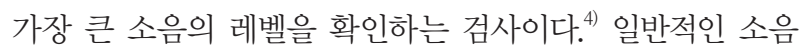
하 청력검사와 다른 점은 소음 환경 속에서 얼마나 잘 들을 수 있는지를 확인하는 것이 아니라, 최적안정역치(the most comfortable level of loudness, MCL)의 말소리를 듣기 위해 얼마나 큰 배경소음을 견딜 수 있는지 측정한다는 점이다. ANL은 피험자가 수용 가능한 다화자(multi-talker)의 최대 소음 양을 스스로 선택하므로 소음 속 어음인지 시 수용 가 능한 소음의 정도를 주관적으로 평가할 수 있다. ANL은 청 력 역치, ${ }^{4)}$ 나이, ${ }^{5,6)}$ 성별ㄱㄱㄱ 유의한 상관성이 없었고, 난청 환 자를 대상으로 한 연구에서는 ANL이 보청기 착용의 만족도 와 착용 시간을 예측할 수 있는 요인이라고 보고되었다. ${ }^{5,8}$ 또 한 정상 청력인 경우, $\mathrm{ANL}$ 값이 높고 낮음에 따라 청성뇌간 반응 및 중후기 잠복반응(middle and late latency response) 이 차이가 있어 $\mathrm{ANL}$ 의 차이는 중추 청각신경계에서 관여한 다고 제안되었다." 이에 본 연구에서는 $\mathrm{ANL}$ 을 보청기 및 인 공와우 환자 등에게 임상적으로 적용하기에 앞서 정상 청력 인 젊은 성인들을 대상으로 하여 한국어로 제작된 $\mathrm{ANL}$ 검 사 결과를 분석하고, $\mathrm{ANL}$ 수치와 청성뇌간반응과의 관련성 을 조사하고자 하였다.

\section{대상 및 방법}

자발적인 지원자 중 난청, 이명 등 이과적 증상이 없고 고막 이 정상 소견이며 순음청력검사상 양측 귀의 모든 주파수에 서 $25 \mathrm{~dB}$ 이하로 정상 청력이 확인된 젊은 성인 53 명(평균 나이 27.0 5.2 세, 범위 19 39세; 남자 23명, 여자 30명)을 대 상으로 하였다. 병력청취, 이내시경 검사, 순음청력검사, 어음 청력검사, 청성뇌간반응 검사, $\mathrm{ANL}$ 검사를 시행하였으며, 18 세 이하의 소아 또는 청소년 및 65세 이상의 노인, 이전에 난 청이나 어지럼증 등의 병력이 있는 자, 급성 또는 만성 중이염 의 병력이 있는 자, 정상 고막 소견을 보이지 않는 자, 순음청 력검사 및 어음청력검사상 정상 청력이 아닌 자는 연구 대상 에서 제외하였다.

순음청력검사는 순음청력기기(Orbiter 922; GN Otometrics, Copenhagen, Denmark)와 헤드폰(TDH-39P; Telephonics, New York, NY, USA)을 이용하여 250, 500, 1 k, 2 k, 3 k, $4 \mathrm{k}, 8 \mathrm{k} \mathrm{Hz}$ 의 주파수를 검사하였다. 모든 주파수에서 $5 \mathrm{~dB}$
상승-하강법에 의해 역치를 구하였고, 모든 환자에서 양측 귀 를 대상으로 검사를 진행하였다. 순음청력 평균은 $500,1 \mathrm{k}$, $2 \mathrm{k}, 3 \mathrm{k} \mathrm{Hz}$ 역치의 합을 4등분하여 소수점 둘째 자리 이하 는 버리고 구하였다. 어음청력검사를 통해 얻은 어음청취역 치(speech reception threshold)에서부터 음강도를 $5 \mathrm{~dB}$ 간 격으로 높이면서 $\mathrm{ANL}$ 검사의 목표 어음을 조용한 환경에서 들려주었을 때 피검자가 가장 편안하게 느끼는 강도인 최적안 정역치 $(\mathrm{MCL})$ 를 확인하였고, $\mathrm{MCL}$ 에서부터 음강도를 $5 \mathrm{~dB}$ 간격으로 높이면서 $\mathrm{ANL}$ 검사의 목표 어음을 들려주었을 때 자극음으로부터 불쾌감이나 압박감, 통증 등을 느끼는 강도 인 불쾌역치(uncomfortable level of loudness, UCL)를 구하였 다. 청성뇌간반응 검사는 Bio-logic Navigator ${ }^{\circledR}$ Pro Evoked Potential System(Natus Medical Inc., San Carlos, CA, USA) 을 사용하였고, 클릭음을 $90 \mathrm{~dB}$ 강도로 주었을 때의 I, III, $\mathrm{V}$ 파의 잠복기를 측정하였다. I, III, V 파형이 확실히 나타나 지 않거나 IV-V 복합파가 관찰되는 경우는 연구 대상에서 제 외하였다.

$\mathrm{ANL}$ 검사는 한국어로 제작된 $\mathrm{CD}$ 를 이용하였고, 스피커 위치는 피검자로부터 정면에서 $1 \mathrm{~m}$ 거리에 위치시켰다. ${ }^{10,11}$ 목표 이야기를 남성 목소리로, 배경소음을 8명(남자 4명+여 자 4명)의 화자로 하여 피검자에게 실제 소음이 있는 상황에 서 듣게 되는 환경을 만들어주었다. 목표 어음을 피검자의 $\mathrm{MCL}$ 수준에서 들려주고 동시에 배경 화자 소음을 제시해 피 검자가 최대로 수용할 수 있는 배경소음수준(background noise level, BNL)을 측정하였다(Appendix). ANL 값은 MCL 에서 $\mathrm{BNL}$ 을 뺄셈을 하여 계산하였다( $\mathrm{ANL}=\mathrm{MCL}-\mathrm{BNL})$. 본 연구에서 $\mathrm{BNL}$ 은 어음청취역치보다 $10 \mathrm{~dB}$ 높은 값에서 시작하여 $2 \mathrm{~dB}$ 단위로 조절하였고, $\mathrm{MCL}, \mathrm{BNL}$ 검사는 각각 두 번씩 진행하여 평균값으로 $\mathrm{ANL}$ 결과를 산출하였다. $\mathrm{ANL}$ 값이 $6 \mathrm{~dB}$ 이하인 경우는 낮은 $\mathrm{ANL}$ 군 $(\mathrm{n}=34), 14 \mathrm{~dB}$ 이상인 경우는 높은 $\mathrm{ANL}$ 군 $(\mathrm{n}=6)$ 으로 정의하였다.

모든 통계적 처리는 SPSS 12.0판(SPSS Inc., Chicago, IL, $\mathrm{USA}$ )을 이용하여 실시하였다. S남녀 간 순음청력 평균, $\mathrm{MCL}$, $\mathrm{BNL}, \mathrm{ANL}$ 을 비교하고, $\mathrm{ANL}$ 값이 높고 낮은 두 군 간의 연 령, 성별, 청성뇌간반응 잠복기의 결과를 비교하기 위해 MannWhitney U-test를 이용하였다. MCL, UCL, BNL, ANL 간의 상관관계는 Spearman correlation coefficient를 통해 통계 적인 유의성을 확인하였다. 각각의 변수들은 평균표준편차 의 형식으로 기술되었고, 유의수준은 0.05 미만을 의미 있는 것으로 해석하였다. 이 연구는 본 병원의 기관윤리심의위원회 의 심의 IRB(No. EMIRB 15-27)를 통과하였다. 


\section{결 과}

정상 청력인 53 명의 대상자에서 $\mathrm{MCL}$ 의 평균은 $35.2 \pm$ 5.3(범위 17.5 45.0) $\mathrm{dB}$ 이었고, $\mathrm{BNL}$ 은 평균 30.2 \pm 6.1 (범위

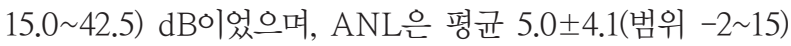
$\mathrm{dB}$ 이었다. $\mathrm{UCL}$ 의 평균은 $55.0 \pm 6.1$ (범위 45.0 67.5) $\mathrm{dB}$ 이었 고, $\mathrm{UCL}$ 과 $\mathrm{MCL}, \mathrm{BNL}, \mathrm{ANL}$ 간에 각각 유의한 상관성이 없었다(Table 1). $\mathrm{ANL}$ 은 $\mathrm{MCL}$ 과 상관성이 없었으나 $\mathrm{BNL}$ 과 유의한 상관성이 있었고, MCL은 BNL과 유의한 상관성이 있었다. 남자 23명의 MCL은 평균 35.4 $\pm 5.2 \mathrm{~dB}$ 이었고, $\mathrm{BNL}$ 은 평균 $30.9 \pm 5.9 \mathrm{~dB}$ 이었으며, $\mathrm{ANL}$ 은 평균 $4.5 \pm 4.5 \mathrm{~dB}$ 이 었다. 여자 30 명의 $\mathrm{MCL}$ 은 평균 $35.0 \pm 5.5 \mathrm{~dB}$ 이었고, $\mathrm{BNL}$ 은

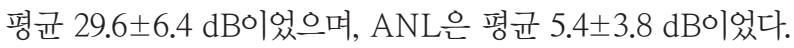
남녀 간에 순음청력 평균, $\mathrm{MCL}, \mathrm{BNL}, \mathrm{ANL}$ 의 평균값들은 유의한 차이가 없었다(Table 2).

$\mathrm{ANL}$ 결과가 $6 \mathrm{~dB}$ 이하인 34명에서 청성뇌간반응의 평균 잠복기는 우측 I 파 $1.46 \pm 0.13 \mathrm{~ms}$, 좌측 I 파 $1.43 \pm 0.15 \mathrm{~ms}$, 우측 III 파 $3.56 \pm 0.14 \mathrm{~ms}$, 좌측 III 파 $3.62 \pm 0.12 \mathrm{~ms}$, 우측 $\mathrm{V}$ 파 $5.26 \pm 0.40 \mathrm{~ms}$, 좌측 $\mathrm{V}$ 파 $5.39 \pm 0.18 \mathrm{~ms}$ 였다. I-III 파 간 잠복기는 우측 $2.12 \pm 0.13 \mathrm{~ms}$, 좌측 $2.18 \pm 0.15 \mathrm{~ms}$ 였고,
$\mathrm{I}-\mathrm{V}$ 파 간 잠복기는 우측 $3.81 \pm 0.27 \mathrm{~ms}$, 좌측 $3.96 \pm 0.18 \mathrm{~ms}$ 이었다. ANL 값이 $14 \mathrm{~dB}$ 이상인 6 명에서는 우측 I 파 $1.42 \pm$ $0.06 \mathrm{~ms}$, 좌측 I 파 $1.38 \pm 0.11 \mathrm{~ms}$, 우측 III 파 $3.52 \pm 0.13 \mathrm{~ms}$, 좌측 III 파 $3.50 \pm 0.11 \mathrm{~ms}$, 우측 $\mathrm{V}$ 파 $5.38 \pm 0.23 \mathrm{~ms}$, 좌측 $\mathrm{V}$ 파 $5.33 \pm 0.24 \mathrm{~ms}$ 였다. I-III 파 간 잠복기는 우측 $2.11 \pm 0.14 \mathrm{~ms}$, 좌측 $2.13 \pm 0.14 \mathrm{~ms}$ 이었고, $\mathrm{I}-\mathrm{V}$ 파 간 잠복기는 우측 $3.94 \pm$ $0.16 \mathrm{~ms}$, 좌측 $3.96 \pm 0.19 \mathrm{~ms}$ 였다. 두 군 간에 남녀 성비, 평 균 나이, 청성뇌간반응 검사상 $\mathrm{I}, \mathrm{III}, \mathrm{V}$ 파의 평균 잠복기 및 I-III, I-V 파 간 잠복기는 유의한 차이가 없었다(Table 3).

\section{고 찰}

수용소음레벨(ANL)은 최적안정역치(MCL)와 배경소음 수준(BNL)의 차이를 통해 대상자가 목표 어음을 듣는 동안 최대로 수용할 수 있는 배경 화자 소음의 수준이 얼마인지를 측정하는 것이다. ${ }^{410}$ 소음하 환경에서 얼마나 잘 들을 수 있 는지를 측정하는 검사들과는 달리 목표 어음을 듣는 동안 다 화자(multi-talker)의 배경소음을 얼마나 잘 참을 수 있는지 를 정량화하는 검사로서, $\mathrm{ANL}$ 이 주관적인 느낌을 평가하는 도구이지만 특히 보청기 사용에 대한 만족도 및 성공 예측

Table 1. Correlations among the most comfortable level of loudness (MCL), uncomfortable level (UCL), background noise level (BNL) and acceptable noise level (ANL)

\begin{tabular}{|c|c|c|c|c|}
\hline & $\mathrm{MCL}$ & $\mathrm{UCL}$ & BNL & ANL \\
\hline \multicolumn{5}{|l|}{$\overline{M C L}$} \\
\hline Coefficient & 1 & 0.25 & 0.78 & 0.11 \\
\hline$p$-value & & $>0.05$ & $<0.001$ & $>0.05$ \\
\hline \multicolumn{5}{|l|}{ UCL } \\
\hline Coefficient & 0.25 & 1 & 0.22 & -0.05 \\
\hline$p$-value & $>0.05$ & & $>0.05$ & $>0.05$ \\
\hline \multicolumn{5}{|l|}{ BNL } \\
\hline Coefficient & 0.78 & 0.22 & 1 & -0.54 \\
\hline$p$-value & $<0.001$ & $>0.05$ & & $<0.001$ \\
\hline \multicolumn{5}{|l|}{ ANL } \\
\hline Coefficient & 0.11 & -0.05 & -0.54 & 1 \\
\hline$p$-value & $>0.05$ & $>0.05$ & $<0.001$ & \\
\hline
\end{tabular}

Table 2. Comparison of mean acceptable noise level (ANL) between male and female

\begin{tabular}{|c|c|c|c|}
\hline & Male $(n=23)$ & Female $(n=30)$ & $p$-value \\
\hline PTA's, right $(\mathrm{dB})$ & $4.6 \pm 2.9$ & $4.5 \pm 3.1$ & $>0.05$ \\
\hline PTA's, left (dB) & $4.7 \pm 3.2$ & $4.4 \pm 2.8$ & $>0.05$ \\
\hline SRT, right ( $d B)$ & $4.6 \pm 4.0$ & $4.3 \pm 2.8$ & $>0.05$ \\
\hline SRT, left (dB) & $4.9 \pm 3.6$ & $4.8 \pm 3.7$ & $>0.05$ \\
\hline $\mathrm{MCL}(\mathrm{dB})$ & $35.4 \pm 5.2$ & $35.0 \pm 5.5$ & $>0.05$ \\
\hline $\mathrm{BNL}(\mathrm{dB})$ & $30.9 \pm 5.9$ & $29.6 \pm 6.4$ & $>0.05$ \\
\hline ANL (dB) & $4.5 \pm 4.5$ & $5.4 \pm 3.8$ & $>0.05$ \\
\hline
\end{tabular}

PTA's: pure-tone average, SRT: speech reception threshold, MCL: the most comfortable level of loudness, BNL: background noise level 
Table 3. Comparison of demographic and audiometric data between low and high acceptable noise level (ANL) groups

\begin{tabular}{|c|c|c|c|}
\hline & Low ANL group ( $\leq 6 \mathrm{~dB}, \mathrm{n}=34)$ & High ANL group $(\geq 14 \mathrm{~dB}, \mathrm{n}=6)$ & $p$-value \\
\hline$\overline{M: F}$ & $14: 20$ & $2: 4$ & $>0.05$ \\
\hline Mean age (year) & $26.5 \pm 5.2$ & $27.5 \pm 3.3$ & $>0.05$ \\
\hline Mean ANL (dB) & $3.9 \pm 2.6$ & $14.7 \pm 0.5$ & $<0.001$ \\
\hline \multicolumn{4}{|c|}{ ABR wave I latency (ms) } \\
\hline Right & $1.46 \pm 0.13$ & $1.42 \pm 0.06$ & $>0.05$ \\
\hline Left & $1.43 \pm 0.15$ & $1.38 \pm 0.11$ & $>0.05$ \\
\hline \multicolumn{4}{|c|}{ ABR wave III latency (ms) } \\
\hline Right & $3.56 \pm 0.14$ & $3.52 \pm 0.13$ & $>0.05$ \\
\hline Left & $3.62 \pm 0.12$ & $3.50 \pm 0.11$ & $>0.05$ \\
\hline \multicolumn{4}{|c|}{ ABR wave $V$ latency (ms) } \\
\hline Right & $5.26 \pm 0.40$ & $5.38 \pm 0.23$ & $>0.05$ \\
\hline Left & $5.39 \pm 0.18$ & $5.33 \pm 0.24$ & $>0.05$ \\
\hline \multicolumn{4}{|l|}{ ABR IPL I-III (ms) } \\
\hline Right & $2.12 \pm 0.13$ & $2.11 \pm 0.14$ & $>0.05$ \\
\hline Left & $2.18 \pm 0.15$ & $2.13 \pm 0.14$ & $>0.05$ \\
\hline \multicolumn{4}{|l|}{ ABR IPL I-V (ms) } \\
\hline Right & $3.81 \pm 0.27$ & $3.94 \pm 0.16$ & $>0.05$ \\
\hline Left & $3.96 \pm 0.18$ & $3.96 \pm 0.19$ & $>0.05$ \\
\hline
\end{tabular}

ABR: auditory brainstem response, IPL: interpeak latency

Table 4. Comparison of mean acceptable noise level (ANL) in young adults with normal hearing

\begin{tabular}{llllccccc}
\hline \multicolumn{1}{c}{ Author } & Year & Language & $\mathrm{n}$ & Mean age & $\mathrm{M}: \mathrm{F}$ & Mean MCL & Mean BNL & Mean ANL \\
\hline Nabelek, et al. & 1991 & English & 15 & 29 & $9: 6$ & $63.8 \pm 9.2$ & $47.9 \pm 8.4$ & $15.9 \pm 8.5$ \\
Nichols and & 2012 & English & 70 & 27 & $21: 49$ & $52.0 \pm 6.0$ & $45.0 \pm 7.3$ & $7.6 \pm 6.9$ \\
$\quad$ Gordon-Hickey & & & & & & & \\
Brännström, et al. $^{13)}$ & 2012 & Swedish & 40 & 28 & $9: 31$ & $65.3 \pm 11.3$ & $54.7 \pm 14.1$ & $10.6 \pm 7.7$ \\
Chen, et al. $^{14)}$ & 2011 & Chinese & 31 & 25 & $15: 16$ & $40.3 \pm 6.3$ & $32.7 \pm 5.0$ & $7.6 \pm 5.0$ \\
Shin and Lee & 2010 & Korean & 20 & 26 & $9: 11$ & $34.3 \pm 4.7$ & $26.5 \pm 4.1$ & $7.8 \pm 4.2$ \\
This study & 2016 & Korean & 53 & 27 & $23: 30$ & $35.2 \pm 5.3$ & $30.2 \pm 6.1$ & $5.0 \pm 4.1$ \\
\hline
\end{tabular}

MCL: the most comfortable level of loudness, BNL: background noise level

을 평가할 수 있는 객관적인 수치를 제시할 수 있다는 점에 서 임상적으로 의미가 있다. 즉, $\mathrm{ANL}$ 수치가 높을수록 배경 소음을 수용할 수 있는 수준이 낮기 때문에 보청기를 착용 할 시 제한이 될 수 있다.5,10,15) Nabelek 등은 으보청기를 사용 하는 191명의 난청 환자들 중 10시간 이상(full time user)으 로 보청기를 사용한 환자들이 필요할 때만(part time user) 사 용한 환자들에 비해 배경소음을 더 잘 수용하고, ANL $10 \mathrm{~dB}$ 이면 보청기 성공 가능성이 $50 \%$ 정도라고 제안하였다. 보청 기뿐만 아니라 인공와우 ${ }^{16,17)}$ 환자에서도 유용성이 보고되고 있어, 저자들은 보청기나 인공와우 착용자들을 대상으로 $\mathrm{ANL}$ 검사를 시행하기 전에 본 연구를 통해 정상 청력을 가진 젊은 성인에서의 $\mathrm{ANL}, \mathrm{MCL}, \mathrm{BNL}$ 을 확인하여 향후 진행될 후속 연구들에서 참고 자료로 활용할 수 있도록 하였다.

정상 청력인 53명의 대상자에서 $\mathrm{ANL}$ 의 평균은 $5.0 \pm 4.1$ (범위 -2 15) dB로 Table 4의 다른 연구들에 비해 상대적으
로 적은 값을 보였다. Shin과 Lee ${ }^{10)}$ 가 한국형 ANL 검사를 개발하면서 정상 청력의 성인을 대상으로 실시한 결과, 배경 소음 화자 수가 증가함에 따라 낮은 ANL 수치를 보여 배경 화자 수와 ANL이 반비례 관계임을 보고하였다. 배경소음 인 원이 증가할수록 어음인지에 영향이 덜 미친다는 것을 나타 내는 바, 본 연구에서는 배경소음을 8명(남자 4명+여자 4명) 의 화자로 하여 타 연구들보다 ANL 평균값이 적게 나왔을 가능성이 있다. ANL 초기 연구들에서는 배경 화자가 1 인(남 자 또는 여자), 2명(남1+여1), 4명(남2+여2), 8명(남4+여4) 등 다양한 방법으로 검사되었으나, 충분히 많은 수의 배경 화자 에서 $\mathrm{ANL}$ 의 검사-재검사 신뢰도가 높다는 최근의 보고들 ${ }^{13,14)}$ 을 반영하여 이번 연구에서는 8 명의 배경 화자를 이용하 였다. 또한, 언어 재료의 유형이 ANL 결과에 영향을 미친다 는 보고들 ${ }^{13,18}$ 로 미루어 한국어의 언어적 특성이 영어를 비롯 한 외국어와 다른 점도 $\mathrm{ANL}$ 평균값이 다르게 나온 또 다른 
이유가 될 수 있다. 측정된 ANL 결과를 판독함에 있어 아직 까지 보고자와 연구기관에 따라 다소 다른 언어와 방법으로 통일된 기준이 정립되어 있지 않아 검사기관마다 참고치를 가 지고 있는 것이 좋을 것으로 판단된다.

$\mathrm{ANL}, \mathrm{MCL}, \mathrm{BNL}$, 불쾌역치(UCL)의 상관관계에서 $\mathrm{ANL}$ 은 $\mathrm{MCL}, \mathrm{UCL}$ 과 관련이 없었고, $\mathrm{BNL}$ 과 유의한 상관성이 있었다. 이는 $\mathrm{ANL}$ 값을 결정하는 주요인이 $\mathrm{BNL}$, 즉 배경소 음임을 암시한다. ANL은 청력 역치 ${ }^{4)}$ 및 나이 ${ }^{5,6}$ 와 관련이 없 고, 소아에서 성인으로 성장하는 시기에도 변하지 않으며, ${ }^{19)}$ 여러 다른 연령군에서 비슷한 분포, 비슷한 평균과 표준편차 를 보인다 ${ }^{4,7)}$ 는 점들은 $\mathrm{ANL}$ 자체가 배경소음에 대한 개개인 의 고유한 내재적인 특성임을 시사한다. 그럼에도 불구하고 $\mathrm{BNL}$ 을 직접 이용하기보다 $\mathrm{MCL}$ 을 보완하여 $\mathrm{ANL}$ 을 계산 하는 것은 단순히 조용한 환경에서의 무의미한 소음을 견디 는 것이 아니라 어음인지 상황에서의 배경소음을 수용하는 정도를 정확히 평가하기 위함이다. 남녀 간에 $\mathrm{ANL}, \mathrm{MCL}$, $\mathrm{BNL}$ 평균값이 차이가 없는 결과는 다른 연구들 ${ }^{4,12,13)}$ 과 일 치하지만, $\mathrm{ANL}$ 값이 $6 \mathrm{~dB}$ 이하로 낮은 군과 $14 \mathrm{~dB}$ 이상으 로 높은 군 간에 청성뇌간반응 검사상 I, III, $\mathrm{V}$ 파의 평균 잠 복기의 차이가 없는 것은 기존의 보고 ${ }^{9}$ 와 일치하지 않는 소 견이다.

이번 연구의 한계 중 하나는 배경소음을 8명으로 제한하 여, 배경 화자가 4 명, 2 명, 1 명인 경우를 검사하지 않은 점이 다. 또한 10 대 후반에서 30 대까지의 정상 청력을 가진 젊은 성인만을 대상으로 하였고 난청 환자나 노인을 포함하지 않 았는데, 후속 연구에서 청력이 정상인 노인들과 보청기를 사 용하는 환자를 포함하여 진행할 예정이다. 기존의 연구에서 제시한 대로 ${ }^{11,20)}$ 본 연구에서는 $6 \mathrm{~dB}$ 이하를 낮은 $\mathrm{ANL}$ 군, $14 \mathrm{~dB}$ 이상을 높은 ANL군으로 나누어 비교하였으나, $14 \mathrm{~dB}$ 이상의 ANL 값을 보이는 대상자가 6명에 불과한 점도 본 연 구의 제한 중 하나이다. 높은 $\mathrm{ANL}$ 군과 낮은 $\mathrm{ANL}$ 군 간에 청성뇌간반응 $\mathrm{V}$ 파의 진폭이 의미있는 차이를 보였다고 보고 하였으나, ${ }^{21)}$ 이번 연구에서는 청성뇌간반응 검사상 잠복기만 분석하였고, 진폭을 측정하지는 못하였다.

\section{Acknowledgments}

This study was supported by Grant of Hanlim Pharmaceutical Co., Ltd, Korea with the approval of the Institutional Review Board of Eulji Medical Center.

\section{REFERENCES}

1) Guide for the evaluation of hearing handicap. JAMA 1979;241(19): 2055-9.

2) Moon SK, Mun HA, Jung HK, Soli SD, Lee JH, Park K. Development of sentences for Korean hearing in noise test (KHINT). Korean J
Otolaryngol-Head Neck Surg 2005;48(6):724-8.

3) Park KH, Kim HS, Kim YH, Park SW, Hong SM, Cho JH. The analysis of loudness discomfort level and hyperacusis in tinnitus patients. Korean J Otolaryngol-Head Neck Surg 2002;45(6):561-8.

4) Nabelek AK, Tucker FM, Letowski TR. Toleration of background noises: relationship with patterns of hearing aid use by elderly persons. J Speech Hear Res 1991;34(3):679-85.

5) Nabelek AK, Freyaldenhoven MC, Tampas JW, Burchfiel SB, Muenchen RA. Acceptable noise level as a predictor of hearing aid use. J Am Acad Audiol 2006;17(9):626-39.

6) Freyaldenhoven MC, Smiley DF, Muenchen RA, Konrad TN. Acceptable noise level: reliability measures and comparison to preference for background sounds. J Am Acad Audiol 2006;17(9): 640-8.

7) Rogers DS, Harkrider AW, Burchfield SB, Nabelek AK. The influence of listener's gender on the acceptance of background noise. J Am Acad Audiol 2003;14(7):372-82; quiz 401.

8) Nabelek AK, Tampas JW, Burchfield SB. Comparison of speech perception in background noise with acceptance of background noise in aided and unaided conditions. J Speech Lang Hear Res 2004; 47(5):1001-11.

9) Tampas JW, Harkrider AW. Auditory evoked potentials in females with high and low acceptance of background noise when listening to speech. J Acoust Soc Am 2006;119(3):1548-61.

10) Shin JB, Lee JH. Effects of the target talker gender and the number of competing talkers on acceptable noise level (ANL) of Korean normal-hearing adults. Audiology 2010;6(2):146-52.

11) Ahn HJ, Bahng J, Lee JH. Measurement of acceptable noise level with background music. J Audiol Otol 2015;19(2):79-84.

12) Nichols AC, Gordon-Hickey S. The relationship of locus of control, self-control, and acceptable noise levels for young listeners with normal hearing. Int J Audiol 2012;51(4):353-9.

13) Brännström KJ, Lantz J, Nielsen LH, Olsen SØ. Acceptable noise level with Danish, Swedish, and non-semantic speech materials. Int J Audiol 2012;51(3):146-56.

14) Chen J, Zhang H, Plyler PN, Cao W, Chen J. Development and evaluation of the Mandarin speech signal content on the acceptable noise level test in listeners with normal hearing in mainland China. Int J Audiol 2011;50(6):354-60.

15) Kim JH, Lee JH, Lee HK. Advantages of binaural amplification to acceptable noise level of directional hearing aid users. Clin Exp Otorhinolaryngol 2014;7(2):94-101.

16) Donaldson GS, Chisolm TH, Blasco GP, Shinnick LJ, Ketter KJ, Krause JC. BKB-SIN and ANL predict perceived communication ability in cochlear implant users. Ear Hear 2009;30(4):401-10.

17) Dingemanse JG, Goedegebure A. Application of noise reduction algorithm ClearVoice in cochlear implant processing: effects on noise tolerance and speech intelligibility in noise in relation to spectral resolution. Ear Hear 2015;36(3):357-67.

18) Koch X, Dingemanse G, Goedegebure A, Janse E. Type of speech material affects acceptable noise level test outcome. Front Psychol 2016;7:186.

19) Moore R, Gordon-Hickey S, Jones A. Most comfortable listening levels, background noise levels, and acceptable noise levels for children and adults with normal hearing. J Am Acad Audiol 2011; 22(5):286-93.

20) Gordon-Hickey S, Moore RE. Influence of music and music preference on acceptable noise levels in listeners with normal hearing. J Am Acad Audiol 2007;18(5):417-27.

21) Harkrider AW, Tampas JW. Differences in responses from the cochleae and central nervous systems of females with low versus high acceptable noise levels. J Am Acad Audiol 2006;17(9):667-76. 


\section{Appendix}

\section{ANL instructions Korea}

지금부터 스피커를 통해 어떠한 이야기를 듣게 되실 겁니다. 듣고 계신 이야기가 본인에게 매우 크게, 매우 작게, 그리고 아 주 편안하게 들리는 세 가지 소리수준을 측정하겠습니다. 소리를 크게 해달라고 요청할 때는 엄지손가락을 위로, 소리를 작 게 해달라고 요청할 때는 엄지손가락을 아래로 향하게 수신호 해주세요.

$\mathrm{MCL}$ : 첫 번째, 듣고 계신 이야기를 매우 크지만 참을 수 있는 정도의 소리 수준으로 높이고자 합니다. 본인이 참을 수 있 을 정도로 큰 소리가 될 때까지 엄지손가락을 위로 올리는 수신호를 반복해주세요. 그 수준이 되면 손으로 “그만”의 표시를 하세요.

두 번째, 듣고 계신 이야기를 매우 작지만 들릴 수 있을 정도의 소리 수준으로 내리고자 합니다. 본인에게 아주 작게 들릴 정도로 작은 소리가 될 때까지 엄지손가락을 아래로 내리는 수신호를 반복해주세요. 그 수준이 되면 손으로 “그만”의 표시를 하세요.

세 번째, 이야기가 본인에게 매우 편안하게 들리는 소리 수준을 찾고자 합니다. 앞서 사용한 수신호를 사용해서 소 리를 크게 혹은 작게 조정해 달라고 요청하세요.

$\mathrm{BNL}$ : 이제까지 들었던 이야기(듣고자 하는 목표 이야기)를 다른 배경 소음(웅성거리는 소리)과 함께 들려드리겠습니다. 본 인이 시끄러운 식당에 앉아 앞사람의 이야기를 듣고 있다고 상상해 보세요. 배경 소음이 시끄럽지만 앞사람의 이야 기가 잘 들리는 수준이라면 어느 정도 참을 수 있을 것입니다. 마찬가지로 이제까지 들었던 이야기(목표 이야기)가 잘 들리면서, 배경소음(식당 웅성거림처럼)은 시끄럽지만 참을 수 있는 소리 수준을 찾겠습니다. 이제까지 들었던 이야 기 소리 강도는 그대로이고 배경소음을 본인의 수신호에 맞추어 조정해드릴 테니 배경소음을 작게 해달라고 요청할 때는 엄지손가락을 아래로 향하게 수신호 하시고 소리를 크게 해달라고 요청할 때는 엄지손가락을 위로, 소리를 작 게 해달라고 요청할 때는 엄지손가락을 아래로 내리는 수신호를 해주세요. 앞의 말씀대로 이야기 소리(목표 이야기) 가 잘 들리면서, 배경소음은 시끄럽지만 참을 수 있는 소리 수준이 되면 손으로 “그만”의 표시를 하세요.

MCL: the most comfortable level of loudness, BNL: background noise level 